\title{
Contemporary Media- A New Generation Information and Entertainment Medium
}

\author{
Dr. Narasimhamurthy $\mathrm{N}$ \\ Associate Professor Dept. of Electronic Media PK Block, Bangalore University, \\ Palace Road, Bangalore-5600 09
}

\begin{abstract}
The present study is to examine how contemporary media of new media is emerging as information and entertainment forms of communication medium for Indian new generation. The $20^{\text {th }}$ century witnessed the emergence of new forms of communication than any other period in history. This new younger is depending on day-today for their information and entertainment through traditional media i.e. the usage of Newspaper, Radio and Television is declining. As successive new media have come into being, ordinary people have started to enjoy the expanded quality, range, and choice of entertainment and information content. Contemporary media of new media play a major role in building and sustaining, democracies, societies, and economics around the world. New media provide citizens with the information necessary to make informed socio-economic and political choices. Technology has powered an explosion of media usage among new generation in the last decade- so much so that these new generation spend as much as time consuming new media in every day. This contemporary media of new media like social media, social networks give a voice to women, youths, and marginalized groups, along with their opinions. The growth of the Internet access and use in India has dramatically altered the ways in which individuals use the new media. The Indian contemporary media scene represents a fast-emerging and influential domain of information exchange and entertainment. The Indian youths are at the forefront of these changes. This fastest growth over the next decades will prove the biggest opportunity for India and especially its youth, whose potential needs to be harnessed rightfully and beyond boundaries.All this changes and growth is in the result of the new media is emerging as a communicative medium of information and entertainment forms for the Indian new generation. The present research is in the nature of empirical. Use, access, and reach of new media among the new generation is correlated with use of this contemporary media as a medium of information and entrainment forms of communication in their daytoday life. The survey research method is followed for data collection.
\end{abstract}

Key words: Contemporary media, New Media, Social Media, New generation, and Bangalore city,

\section{Introduction}

The $20^{\text {th }}$ century witnessed the emergence of new communication than any other period in history with the advent of Internet. The widespread penetration of the Internet and the establishment of the WWW and digital forms of communications facilitated through merger of computers and telecommunications network has been envisaged as the major communication revolution (Fang, 1997). We are now enjoying the benefits of high technology mass media which is not only faster than the traditional mass media, but also a widespread range. Media scholars have argued that the Internet, mobile phones and computers are often referred as new aged media in contemporary era. Internet has opened up several new opportunities for mass communication which include email, websites, podcasts, e-forms, e-books, blogging, Internet TV, and many others which are booming today. Internet has also started social networking sites which have redefined new mass communication all together. Sites like Facebook, Twitter and You Tube have made new communication possibilities to the masses all the more information, entertainment, interesting, and easier. These new communication possibilities have become a boom to mankind at any time and from anywhere. The discovery of Internet can be called the biggest invention in the field of mass media, and it has inspired interaction and connectivity through its social networking medium. In the contemporary era the new age medium has become one of the core means of mass communication medium for new generation. The contemporary media of new media creates its importance in thinking of leading our lives without it will be difficult to this younger new generation.

New media have paved the way to revolutionize all that we thought was either hidden or inaccessible. The key debate about the contemporary media of new media in the contemporary time centers on whether to classify this relatively as a new medium for the information and entertainment forms of communication of new generation. The way in which communication happens through contemporary media, however, is not the same as with traditional mass media such as newspaper, radio, and television. As successive contemporary media of new media have come into being, ordinary people have enjoying on expanded quantity, range and choice of entertainment and information content. The prevalence of the new media is not just a result of its open and 
dynamic nature, its rapid spread has been facilitated by its increased users. The advent of WWW and the free distribution have made new media as a source of information and entertainment medium for younger generation. The contemporary media of new media has made it possible to contact others worldwide, nationally and locally, to send mails and be a part of chat rooms and conferences, blogging with discussion boards, opinion pools and forums, sending and receiving images and files and lots more with every teenager, adult and even senior owning either a personal computer or mobile phones with Internet connection. The new media revolution has made it easier for people to get in touch for their needy information and entertainment. The convergence of new media technology have made impossible has become possible. People virtually get information and entertainment through this contemporary media in a short period. Media culture is pervasive; its messages are an important part of the everyday.

Young people today live in a world characterized dramatic cultural, economic, social and educational differences; individual circumstances depend largely on where a person is born and raised. Lives of young people and their daily activities are structured around media use. New media and online communication have become pervasive in the lives of youth in world and even in India. Engaging in social network sites, online games, video-sharing sites, and gadgets such as iPods and mobile phones are now fixtures of youth culture. Today's youth may be coming of age and struggling for autonomy and identity as did their predecessors, but they are doing so amid reconfigured contexts for communication, friendship, play and self-expression. We are wary of claims that digital generation of new generation is overthrowing culture and knowledge as we know it and that its members are engaging in new media in ways radically different from those of older generation. Our values and norms in education, literacy and public participation are being challenged by shifting landscape of media and communications in which new generation are central actors. Public sentiment is growing around the notion that new generation of youths use new media and communication technologies defines this generation as distinct from their elders. New media empower the new generation to challenge the socio-economic and political issues. The emergent of this new media is closely linked to the younger generation.

\section{The Origin and growth of new media}

The emergent of new media can be traced back to the 1970s, but flourished and come into force in only during the 1990s. The increased capacity of the public telecommunications network and the increased speed of communications modems and personal computers, new media have become an effective worldwide communications medium. The discovery of Internet can be called the biggest invention in mass media. Any new medium us at first a novelty used by a small group of people, later popularization comes and it becomes widespread or a mass medium (Merril $\mathbf{J}$ and Lowenstein). In early days, news used to reach people only in the next day morning. But today, live updates reach us simultaneously as the events unfold. More than any other technologies for mass communication contemporary media of new media allows for greater quantity of information transmission and retrieval in content creation and selection in the hands of their users. The same is occurred with the invention of Internet.

The Internet was initially originated during the cold war, in the second part of the $20^{\text {th }}$ century, for a network of four computers was designed for military purposes by the United State, Department of Defense. Lately this system was called as Advanced Research Projects Agency Network (ARPANET). It was designed as a precaution against the nuclear attack. For a long time the computer network was an egalitarian source of communication, mostly among scholars and scientists, in subsequently it create international research teams. Later, Local Area Networks (LANs) were developed and started to function by Transmission Control Protocol (TCP) and Internet Protocol (IP). The Local Area Networks were connected to Wide Area Networks (WANs). It was happened in 1990s that with the invention of World Wide Web (WWW). It was this system which quickly evolved into a world wide web of information and become the most popular usage of the Internet. The Internet is become user friendly and could be accessible by everyone in everywhere.

Media scholars have argued that the Internet took less time to become a mass medium than did any other technology in the past. Electricity, radio and television took several years to reach masses, but Internet took just four years to reach users. The Internet as we know it began in earnest in 1995, when it was turned over from the military to the public. The growth of information online took off rapidly, in the same period, the commercial sites have started to appear in online and allowed the users to send and receive information. Thus the computer mediated communication of new media provides a chance of communication for information and entertainment with variety of traditional and new audiences without facing any limitation in terms of time, place and content. This is a result of after the beginning of 1990s, the Internet is gained widespread acceptance of all over the world as new generation medium. Media historians have viewed that a mass media revolution takes roughly more than thirty years, but the Internet is truly become an essential medium of new mass media within a short period. In other words, one way traditional communication has been replaced by interactivity. Because of emergent of Internet, the other existing traditional mass media, such as newspaper, radio and television have also undergone changes and become more interactive. 


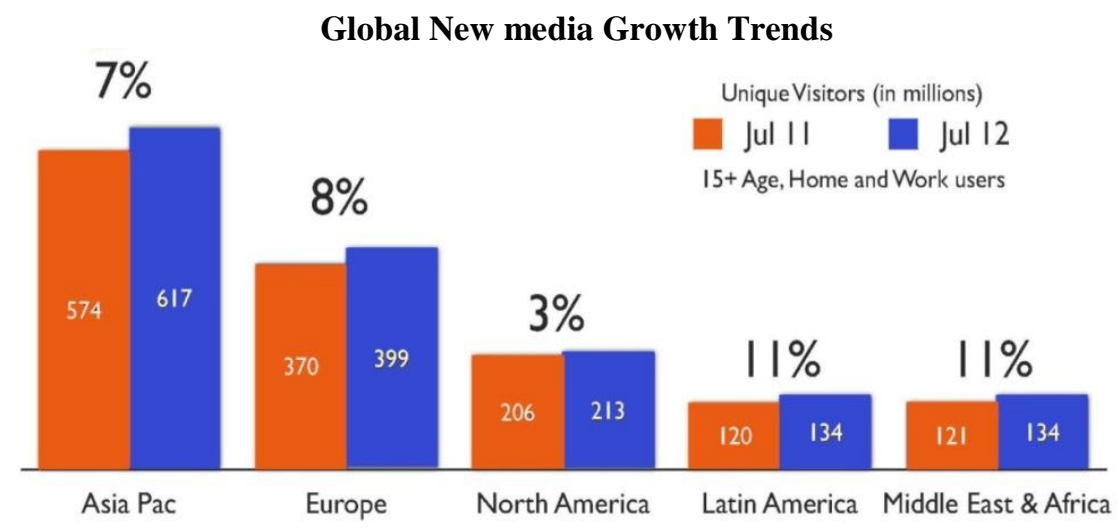

According to International Telecommunication Union in 2013, nearly 2.7 billion people are actively using Internet, which is $39 \%$ of the world's population. Over $31 \%$ online population belongs to Asia, Africa and Latin American countries. Europe is the region with the highest Internet penetration rate in the world. Majority of the Internet users across the globe is male (41\%) compare to female (37\%). Over 1.5 billion male are actively using Internet and 1.3 billion female are actively using Internet globally. The ITU estimates over $28 \%$ household in developing countries have Internet connection and $78 \%$ of the house hold are connected to the Internet in developed countries.

\section{New Media in India}

The contemporary media of new media in India have become increasingly popular components of our younger generation's lives in today's modern society. It provides for new generation to communicate, exchange message, share knowledge, and interact with each other regardless of their distance that separates them. The contemporary media links people across the nation regardless of differences and geographical boundaries. The compression of time and space, the convergence of media and the effects of globalization have made the nation into a more interactive. New generation are feeling more comfortable in use and access of new media for communicating and building relationships through online (Ray2000). The middle age group and adults are very comfortable in use of this technology because they are growing with technological era. The younger generation may not recall how or when they learned to use a computer or access the Internet; for as long as they can remember, those tools were always there. Young people particularly are quick to use the new technology in ways which increasingly blur the boundaries' between their online and offline activities. Contemporary media are also developed rapidly as technology changes with new communication technological dimensions and features. The new generations of youths with in the country, who are growingalong with new communication technologies are emerging as "new generation."

Asia is the largest growing continent when it to be increased in the use and access of new media users across the world. Compare to other worlds the new media users growing rate is $15 \%$ annually in Asian continent. This is clearly shows that Asian nations role in the growth of the users of contemporary media of new medium. The two major countries, namely China and India are important contributors to this growth with over more than 500 million subscribers. New media use also on the rise globally, and this change is also evident is increased in India, several studies and reports found evidence that more adults use new media, social media and social networks in India than in any other Asian countries. Contemporary media of new media uses in India have become more familiar with the web, its role in providing information has expanded and changed. The contemporary media is becoming more and more for new generations attention, not only for searching for information and communications with friends and family but also for the purposes of entertainment. This change is taking eyes away from other traditional media. India is at the race with China in use of new media. India has added around $30 \%$ of the people use new media for different purposes in their day-today lives from past two years, and it is growing at the rate of adding 12.5 million Indian users on year to year. Besides the heavy population India stands last when it comes to the average time spent online per visitors, being 12.5 hours. The usage rates are expected to increase as the Internet penetration increases.

Contemporary media of new media audience in India is very young compared to the rest of the other nations in the world. Nearly $75 \%$ of new media users in India are under the age of below 35 years and nearly half of them are under 25 years of age. These usage patterns show that the expansion, adaptability and future prospects of the new media in India. Searching information, social networking, e-mail are the top most for the users to use new media in their day-today activities in India. Nearly more than $84 \%$ online audience will use social networks for different purpose of communication and other online activities. It is clearly shows that the young generation is leading the contemporary media revolution in India. The growth and use of new media by 
younger generation in India for the purpose of their Information and entertainment is leading and going by the current trends.

Total number of Internet Users in India

\section{Claimed}

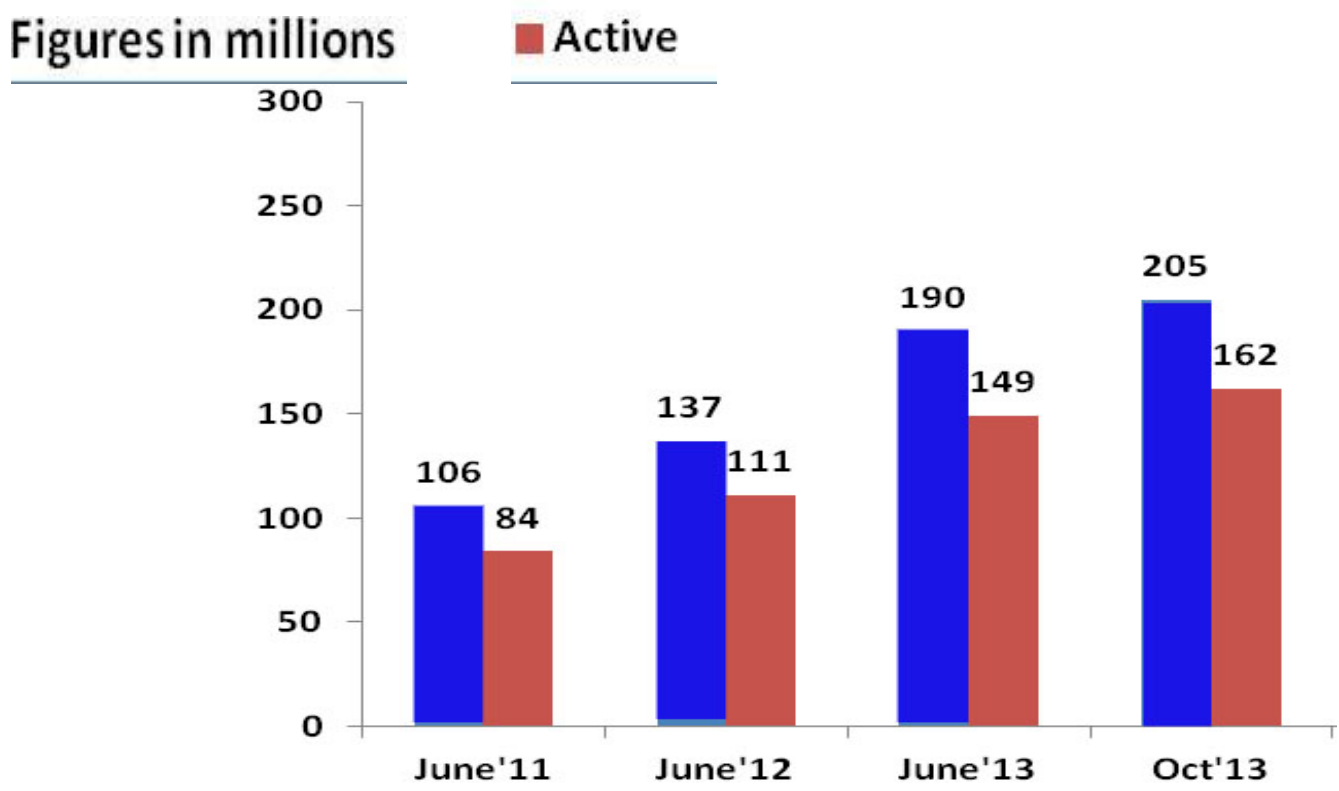

The report released by Internet and Mobile Associationof India the number of Internet users in India is reached 205 million in the year of 2013 it is compared to 137 million in 2012, this increase is shows approximately $40 \%$ growth of new media users in India. Several studies cite that by 2014 new media users in India will cross 234 million. This will make India is the second new media consumption base in the word, it is more than Internet users in United States. Rural Indian new media users number also increasing. According to the report, rural India has seen a 58\% growth in terms of active Internet users, from 38 million in2012 to 60 million in 2013

\section{Contemporary Media and Youths in India}

It is rightly said that while younger generation are the future of the any nation, this youths are its present. The energy enthusiasm, dynamism, innovative ideas and creative thinking they possess make the younger population and important asset for any country's accelerated development. With regard to this younger generation resource, India has a distinct edge over the development nation's most of which will be facing the burden of a fast ageing population in the coming decades. Numbers alone are just part of the story. In order to reap the benefits of the "demographic dividend" it is necessary that these younger men and women are imparted the right kind of education, motivation and exposure and provided with opportunities for the development of their personality and functional capability so as to make them economically and socially useful. A country's economic progress depends on its people, especially the younger generation, having access to the world of knowledge conveyed by the mass media. Various forms of media, such as television, radio, newspapers, cinema, magazines and most notably the contemporary media of new media have impacted on the youth. The media is not only serves as a source of information but also it provides a source of entertainment. Media sources have relentlessly becoming on creating, appealing images that entice the younger generation to their content. This may be more informative and more entertainment for new generation to become coerced into consuming to more time to read or to browsing for such information. The advancement in the field of communication technologies, computers and mobile communication technology has led to ease of access and use of new media. Whereas this advancement and changes is creates a tech-savvy generation of new generation,

There is no doubt that there is a growing population of new generation of youths are ardent users of new media platforms in India. The contemporary media have changed the way of our society connects with one another, does information, entertainment. Today's generations have never known a world without new media. With social networks like Facebook or Twitter, the Indian youths are very much connected with each other with global and local issues through these new media platform. The contemporary media platforms are fast replacing traditional communication channels such as television and radio in India. These media platforms are also utilized by industry, government and other public agencies as a preferred powerful tool of communication to inform, to educate and to entertain the general public. 
There is a need for a better understanding of how the new generations are using contemporary media and how it is likely to affect their lives. It is therefore, noteworthy that the medium is understood. The present research will give an insight as how the contemporary media of new media is the medium of information and entertainment forms of communication for Indian new generation. In the last ten years the new media world has changed dramatically. The invention of new media, young men and women now exchange ideas, feelings, personal information, pictures and videos at a truly astonishing rate. However, every day, many Indian youths are spending countless hours immersed in contemporary media of new media such as social networks. At first glance this may seem like a waste of time, however it also helps youths to develop important knowledge and skills, and active citizen who create and share content. Contemporary media continue to grow in popularity in India, many researchers have been diving into a considerable amount of research on how this new media is influences the new generations medium of information and entertainment. Many scholars and parents in India are worried that the new generations are spending too much time with new media and addictions to social network sites. Therefore the present study is to ascertain the relationship between new media and new generation in India and how these contemporary media will be the medium of information and entertainment.

To address the issues of the effectiveness of new media on younger generation in India, the first question is raised in this study is for what purpose is this generation using new media? Based on this question the present research start to reveal contemporary media of new media are part of their lives and how they interact with each other. Thus the objective of this study is to explore the emergence of new media as medium of information and entertainment for the emerging new generation of the nation. The present research is to examine that how the individuals use the contemporary media for their information and entertainment and various functions of new media in conjunction with conventional media.

To examine the relationship between use of contemporary media and its effects on new generation, the following research questions were proposed:

RQ1: How does younger generation use new media?

RQ2: Whatamount of time spends by the new generations on contemporary media for their information and entertainment?

RQ3: To what extent are younger generations depending on contemporary media for their information and entertainment?

RQ4: What is the impact of contemporary media on new generation?

\section{Methodology}

The present study aims to examining the phenomenon of access, exposure and use of contemporary media in the context of information and entertainment medium of younger generation of the country. For the present study survey research methodology was used to explore to answer the research questions. Survey research is one of the most important areas of measurements in applied social research. The broad area of survey research encompasses any measurement procedures that involve asking questions of the respondents. A "survey" can be anything forms a short paper-and-pencil feedback from to an intensive one-on-one in-depth interview. In this present study I used the questionnaire schedules for data collection. Questionnaires are an inexpensive way to gather data from a potentially large number of respondents. A well-designed questionnaire that is used effectively can gather information on both the overall performance of the respondents. For data collection questionnaires were administered to youths in the age group between 22-25 years. The study was conducted at the Bangalore University, Bangalore, and the data was collected in the month of November 2013. Data was collected through questionnaire consisting of three parts: in the first part it is demographic information of the students, gender and in which stream their study (like studying in Arts, Science, Commerce, etc $\}$ the second part is media ownership and access and last part of the questionnaire is new media effects in their totoday life. The sample for the study was drawn from the Bangalore University students.250 students were selected randomly from the post graduates departments and were asked to fill the questionnaire. For analyzing the data, SPSS program were used.

Media using time: Respondents were asked to how many hours in a day they use Internet for the purposes of Information and entertainment in 1-2 hours 3-4hours, 4-6 hours and more than 6 hours. Subscription of newspaper, owning radio, television, computer and mobile was asked with is the read newspaper watch television and listen radio on the basis of (1-5) Always to Never.

\section{Analysis and findings}

The survey collected demographic data, including age, gender, and major of education. The median age of respondents was $\mathrm{M}=24$ years of age. The respondents representation based on gender. Out of 250 questionnaires we have received 240 schedules out of 240, six schedules were rejected due to non-completion of the questionnaire and finally 234 schedules were selected for analysis. Out of the 234 respondents 42 (17.94\%) respondents were studying in Arts, 43 (18.37\%) students were studying in science, 45 (19.37\%) commerce, 30 
(12.8\%) students perusing engineering, 35 (14.95\%) students studying medical education 27 (11.53\%) students are belongs to law and $12(5.12 \%)$ students are others educations means perusing education, physical education etc. Different gender groups have responded for this research, ot of 234 respondent $150(64.10 \%)$ were male respondents and $84(35.90 \%)$ respondents belong to female respondents.

Table 1.1: Access to the different mass media (Newspaper, Radio, Television, and Mobile Communication, Computer and Internet)

\begin{tabular}{|c|c|c|c|}
\hline & & Frequency & Mean \\
\hline \multirow{3}{*}{ News Paper } & Yes & 127 & 54.27 \\
\cline { 2 - 4 } & No & 107 & 45.72 \\
\cline { 2 - 4 } & Total & 234 & 100 \\
\hline \multirow{3}{*}{ Radio } & Yes & 78 & 33.33 \\
\cline { 2 - 4 } & No & 156 & 66.66 \\
\cline { 2 - 4 } & Total & 234 & 100 \\
\hline \multirow{3}{*}{ Television } & Yes & 183 & 78.20 \\
\cline { 2 - 4 } & No & 51 & 21.79 \\
\cline { 2 - 4 } & Total & 234 & 100 \\
\hline \multirow{3}{*}{ Mobile } & Yes & 229 & 97.86 \\
\cline { 2 - 4 } & No & 5 & 2.136 \\
\cline { 2 - 4 } & Total & 234 & 100 \\
\hline \multirow{3}{*}{ Computer } & Yes & 132 & 56.41 \\
\cline { 2 - 4 } & No & 102 & 43.58 \\
\cline { 2 - 4 } & Total & 234 & 100 \\
\hline \multirow{3}{*}{ Internet } & Yes & 72 & 69.23 \\
\cline { 2 - 4 } & No & 162 & 100 \\
\cline { 2 - 4 } & Total & 234 & \\
\hline
\end{tabular}

Number of respondents $(n=234)$

The above 1.1 table shows that media owning by the respondents, out of 234 respondents $127(54.27 \%)$ were subscribes newspaper in their home and 107 (45.72\%) respondents still did no subscribes the newspaper. $78(33.33 \%)$ respondents said they have radio set in their home and 156(66.66) said they don't have radio set in their home. Out of 234 respondents $183(78.20 \%)$ respondents said they have television in their home and 51 $(21.79 \%)$ respondents said they don't have television in their home. In respect of mobile ownership 229 $(97.86 \%)$ said they have mobile and only 5(2.13\%) said they do not have mobile. About $132(56.41 \%)$ respondents reported having a computers at home. Of these respondents having computers in their home and only $72(30.76 \%)$ of respondents having Internet connection, and $102(43.58 \%)$ respondents expressed they do not have computer and $162(69.23 \%)$ respondents do not have Internet connection in their home. The access of different mass media such as newspaper, radio, television and Internet were considered and recorded among respondents the table 1.1 is clearly shows that still $46 \%$ of Indian house hold did not subscribe the newspaper, television and mobile is largely access communication technology among students.

Table 1.2: Media use and consumption by the students

\begin{tabular}{|c|c|c|c|}
\hline & & Frequency & Mean \\
\hline \multirow{5}{*}{ News Paper } & Always & 52 & 22.22 \\
\hline & Very often & 68 & 29.05 \\
\hline & Sometimes & 59 & 25.21 \\
\hline & Occasionally & 55 & 23.50 \\
\hline & Total & 234 & 100 \\
\hline \multirow{5}{*}{ Radio } & Always & 15 & 6.41 \\
\hline & Very often & 50 & 21.36 \\
\hline & Sometimes & 25 & 10.68 \\
\hline & Occasionally & 144 & 61.53 \\
\hline & Total & 234 & 100 \\
\hline \multirow{5}{*}{ Television } & Always & 132 & 56.41 \\
\hline & Very often & 78 & 33.33 \\
\hline & Sometimes & 21 & 8.97 \\
\hline & Occasionally & 3 & 1.28 \\
\hline & Total & 234 & 100 \\
\hline \multirow{6}{*}{ Daily Internet Usage } & 1-2 hours & 91 & 38.88 \\
\hline & 3-4 hours & 59 & 25.21 \\
\hline & 5-6 hours & 45 & 19.23 \\
\hline & $6+$ & 25 & 10.68 \\
\hline & Never & 14 & 5.98 \\
\hline & Total & 234 & 100 \\
\hline
\end{tabular}

Number of respondents $(n=234)$ 
The students were asked for how long they had been using different media viz., newspaper, radio, television and Internet on daily for their information and entertainment. Out of 234 respondents 52 (22.22\%) respondents they read newspaper always means it is indicate that daily newspaper reading, 68 (29.05\%) respondents were reading newspaper on very often, $59(25.21 \%)$ read newspaper sometimes, $55(23.50 \%)$ respondent says they read new paper in occasionally, but none of them respond they do not read newspaper at all. Radio is another mass media, the students were also asked how long they had been listening programs, only $15(6.41 \%)$ respondents they listen always and $144(61.53 \%)$ students they listen radio programs in occasionally, it shows radio programs are not an important for students. In the context of television usage 132 $(56.41 \%)$ respondents express they watch television always, $78(33.33 \%)$ respondents watch television programs in very often, $31(8.97 \%)$ respondents says they watch television sometimes and only $3(1.28 \%)$ expressed they watch television programs occasionally, it shows television is very popular medium for new generations. The respondents were asked for how long they had been using the Internet. The majority of the respondents had been using Internet at least 1-2 hours in a day 91 (38.88\%) use Internet for different purposes, $59(25.21 \%)$ respondents use Internet 3-4 hours in a day, 45 (19.23\%) respondents express they use Internet nearly 5-6 hours in a day, $25(10.68 \%)$ respondents are using Internet more than six hours in a day for different purposes. The very interesting is nearly $14(5.98 \%)$ respondents are expressed they never use Internet for any purposes. The present study is clearly indicates that the majority of the students use Internet for Information, entertainment and other different purposes. These findings suggest that the younger generation have been exposed to the contemporary media at a very large.

Table 1.3: The usage of Internet for the different purposes

\begin{tabular}{|l|c|c|}
\hline & Frequency & Mean \\
\hline E-mail and chatting only & 54 & 23.07 \\
\hline E-mail and Social networking & 63 & 26.92 \\
\hline Social networking and Chatting & 49 & 20.94 \\
\hline Video games & 27 & 11.53 \\
\hline Connecting with others & 11 & 4.70 \\
\hline Different purposes & 16 & 6.83 \\
\hline Never & 14 & 5.98 \\
\hline Total & 234 & 100 \\
\hline
\end{tabular}

Number of respondents $(n=234)$

In relation to the reason for using the Internet, 54 (23.07\%) respondents stated that they use Internet for sending and receiving e-mails and chatting, 63 (26.92\%) respondents are using Internet for e-mail and social networking, 49 (20.94\%) respondents use Internet for social networking and chatting, nearly 27 (11.53\%) respondents use Internet for playing video games, 11 (4.70\%) respondents use Internet for connecting with others and $16(6.83 \%)$ respondents use Internet for different purposes means it they could not express openly because they were using the Internet for the purposes of to see porn/adult sites and other related information. This findings clearly state that the majority of younger generation use new media for different purposes.

Table 1.4: Using Internet for Information, Entertainment and Education by the respondents

\begin{tabular}{|l|c|c|}
\hline & Frequency & Mean \\
\hline Information and Education & 54 & 23.07 \\
\hline Entertainment and Education & 63 & 26.92 \\
\hline Information and Entertainment & 74 & 31.62 \\
\hline None of the above & 29 & 12.39 \\
\hline Never & 14 & 5.98 \\
\hline Total & 234 & 100 \\
\hline
\end{tabular}

Number of respondents $(n=234)$

The students studying Bangalore University were asked for how Internet is useful their education and information, nearly $54(23.07 \%)$ respondents indicated that it is very useful and I am using Internet for the purpose of information and education, $63(26.92 \%)$ of respondents expressed they use Internet for the purpose of entertainment and education, and very interestingly $74(31.62 \%)$ respondents use Internet for the information and entertainment, 29 (12.39\%) respondents expressed they use Internet for other purpose. This indicates that the contemporary media of new media is very useful and powerful medium for younger generation. 
Table: 1.4: The effects of contemporary media on new generations

\begin{tabular}{|c|c|c|c|}
\hline & & Frequency & Mean \\
\hline \multirow{6}{*}{ Informative } & Strongly Agree & 77 & 32.90 \\
\hline & Agree & 68 & 29.05 \\
\hline & Strongly Disagree & 34 & 14.52 \\
\hline & Disagree & 33 & 14.10 \\
\hline & I don't know & 22 & 9.40 \\
\hline & Total & 234 & 100 \\
\hline \multirow{6}{*}{ Entertainment } & Strongly Agree & 66 & 28.20 \\
\hline & Agree & 76 & 32.47 \\
\hline & Strongly Disagree & 42 & 17.94 \\
\hline & Disagree & 30 & 12.82 \\
\hline & I don't know & 20 & 8.54 \\
\hline & Total & 234 & 100 \\
\hline \multirow{6}{*}{ Education } & Strongly Agree & 68 & 29.05 \\
\hline & Agree & 71 & 30.34 \\
\hline & Strongly Disagree & 38 & 16.23 \\
\hline & Disagree & 32 & 13.67 \\
\hline & I don't know & 25 & 10.68 \\
\hline & Total & 234 & 100 \\
\hline \multirow{6}{*}{ New mass media } & Strongly Agree & 65 & 27.77 \\
\hline & Agree & 76 & 32.47 \\
\hline & Strongly Disagree & 44 & 18.80 \\
\hline & Disagree & 29 & 12.39 \\
\hline & I don't know & 20 & 8.54 \\
\hline & Total & 234 & 100 \\
\hline
\end{tabular}

Number of respondents $(\mathrm{n}=234)$

In relation to the use of new media $77(32.90 \%)$ respondents strongly agree that the contemporary media is very informative for younger generation, $68(29.05 \%)$ respondents agree new media is very informative. Only $34(14.52 \%)$ respondents strongly disagree and $33(14.10 \%)$ respondents are disagree the contemporary media is informative. The above tables reveals that contemporary media of new media is very informative for new generation. In relation to how contemporary media and entrainment the above tables shows a very strong significant, nearly $66(28.20 \%)$ and 76 (32.47\%) Bangalore University students strongly agree and agree the contemporary media is very powerful medium for entertainment. Further the study reveals that how contemporary media of new media is helpful to the new generation for their education-more than $139(55 \%)$ of University students have expressed their opinion it is very useful and helpful, only over $25 \%$ of the students have did not agree the contemporary media or Internet is not helpful for their education. The above table shows that the new media are used extensively for their education. In relation to the question of Internet is an emerging mew mass medium, $65(27.77 \%)$ have strongly agree, 76 (32.47\%) agree, 44 (18.80\%) students strongly disagree and $29(12.39 \%)$ disagree the Internet is emerging as new media. When the students were askedto is Internet is emerging as new mass media, majority of participants have agreed.

\section{Discussion}

The present study was designed to understand that the how contemporary media of new media is the information and entertainment medium for new generations in their lives. Contemporary media and younger generations seem destined for each other; both are young, fast paced and ever changing. In $20^{\text {th }}$ century the younger generation readily embraced by classical media, such as newspaper, radio, and television, but the 21 th century has witnessed a virtual explosion in new communication technologies and these leads to convergence of new media. This contemporary media has been eagerly embraced by new generation and has led to an expanded sharing information and entertainment. The contemporary media has many benefits for the new generations, but caregivers and educators have expressed concern about the dangers new generations can be exposed to through this media.

The result of the study is indicating that the contemporary media is very effective medium for new generation; the younger generation prefers to get information from the Internet rather than books. The participant's response in the context of new media usage is they use contemporary media or not, majority of the respondents replied that they were using new media extensively for information or neither entertainment. They further agree that the new media is enough as a source for entertainment. Since they do not agree with this statement it may suggest that they lack of he necessary skills. In response to relation to the use of the new media for the purpose of education, majority of the respondents have agree that the new media is the best medium and only problem is accessing is the only problem. They further stated that they use contemporary media facilities for e-mail, chatting and educational purposes very extensively. The study is attention on contemporary media and its influence on respondent's opinion in relation to use of information and entertainment concerning 
important issues raised in research questions and it is very significant also. The result of the study is recorded and presented for analysis.

The study finds that there is a good awareness on contemporary media among new generations though majority of respondents were access and use of this contemporary media. This shows that considerable new population has an awarenessand use of contemporary media of their information and entertainment. The study finds that majority of the new generations have attempted to have access and use contemporary media for their well-being and for their future education purposes information and entertainment. It is an evident that the new generations have evinced interest in gain access of contemporary media and use it in their lives. Further the study found that new generation or new emerging youth population found to be dependent on contemporary media in very significant number on the whole them in a significant awareness on contemporary media among new generation. The present study found that Internet and television were the most popular and highly preferred medium. It shows that the contemporary media is found to be the most important and convenient and widely preferred mode of communication medium for new generations compare to other classical media. The other classical media such as newspaper and television are also preferred medium, but surprisingly the cheap and free medium of radio is least preferred by new population. Lastly the study found that contemporary media influence is very high on new generations, this influence shows that new media is emerging as a new mass medium on society.

\section{Conclusion}

Information and entertainment are the basic needs for the human being in modern society. This basic need widely recognized themes in a modern knowledge system. The contemporary media landscape is constantly shifting and factors surroundings new generations use of contemporary media and other new communication technologies for the purpose of information and entertainment are complex. It is all pervasive and integral to the development of contemporary societies. The study suggest that the post graduate students of the Bangalore University widely use Internet both as communication device and as well as information and entertainment medium. In general they agree with the facilities of the contemporary media and they familiar with also. However, majority of the students agree that the contemporary media is significant for the education, information and entertainment. The study finds that the majority of the students are depending on contemporary media for their information, entertainment and education rather than library. Further they consider the contemporary media is the only medium in reaching quickly and easily for new generation. When students consider the contemporary media of new media as a best communication tool they point out that it is the new mass medium for the new generations. It is very easy to access, to establish contacts with friends, parents, and others, this is their means for keeping in touch with their friends and family for information, entertainment and education.

\section{References}

[1]. Alshehri, F. (1997). The Internet as a source of news and information: An analytical study of the news and information about Saudi Arabia on the World Wide Web. Master thesis, Department of Journalism Studies. University of Sheffield, England.

[2]. Alterman, J. (1998). New Media, New Politics: From Satellite Television to the Internet in the Arab World. Washington, D. The Washington Institute for Near East Policy.

[3]. Andrews, W. (1996). Surveillance in cyberspace, American Journalism Review 18, 12

[4]. Arant, M.D., Jr. (1996). The use of online resources in teaching journalism and mass communication. Paper presented at the Annual meeting of AEJMC Communication Technology and Policy Division November, Los Angeles, California.

[5]. Badu, E. E., Markwei, E. D. (2005). Internet Awareness and Use in the University of Ghana. Information Development. Vol. 21. No: 4. pp. 260-268.

[6]. Baer, W. S. (1998). Will the Internet Transform Higher Education? The Emerging Internet, Annual Review of the Institute for Information Studies, Institute for Information Studies

[7]. Barrie Gunter, (2003). News and the Net, Lawrence Erlbaum Associates, New Jersey

[8]. Berthon, P, Pitt,G., \& Watson, G. (1997). The World Wide Web as an advertising medium: towards an understanding of conversion efficiency, Journal of Advertising Research, 36, 43-58.

[9]. Cairncross, F. (2005). The Trendspotter's Guide to New Communications. Living in the Information Age, edited by Bucy, E. P. Canada: Wadsworth Thomson Learning,

[10]. Chan, A, P., \&Maston, T. (1999). Internet use and issue knowledge of the college-age population. Paper presented at the annual meeting of Association of Education in Journalism and Mass Communication, New Orleans, IA

[11]. Fang,I, (1997). A History of mass communication:Six information revolutions. Oxford, England: Focal Press.

[12]. Hong, K. S., Ridzuan, A. A., Kuek, M.K. (2003). Students' Attitudes toward the Use of the Internet for Learning: A Study at a University in Malaysia. Educational Technology and Society. Vol. 6. No: 2

[13]. ITU Publication (The World in 2013). ICT Facts and Figures, Annual Publication.

[14]. Jones, S. (2002). The Internet Goes to College. Washington, DC: Pew Internet \& American Life Project.

[15]. Merril J, \& Lowenstein(1971), Media, message and men: New perspective in Communication, David MacKay, New York

[16]. Nielsen/Net Ratings, (November, 2013). How loyal are your customers-A view of loyalty sentiment around the world.

[17]. Philip N. Howard, Steve Jones (2004). (ed) Society Online- The Internet in Context, Sage Publications New Delhi.

[18]. Rüzgar, N. S., (2005). A Research on the Purpose of Internet Usage and Learning via Internet. Turkish Online Journal of Educational Technology - TOJET. October 2005. Vol. 4. Issue 4. Article 4.

[19]. Toprakçı, E. (2007). The Profiles of the Use of the Internet for Study Purposes Among University Students. The Turkish Online Journal of Educational Technology - TOJET . Vol. 6. No: 3. Article 13.

[20]. Young, K. (2009). The Internet in Tertiary Education: A Survey of Students' Internet Activity. In Proceedings of World Conference on Educational Multimedia, Hypermedia and Telecommunications. 